\title{
Ergonomic Assessment of Occupational Health of Transport Operators
}

\author{
Dr. Payal Raghuvanshi ${ }^{1}$, Dr. Deepa Vinay ${ }^{2}$ \\ Department of Family Resource Management College of Home Science, G. B. Pant University of Agriculture \&Technology; Pantnagar - \\ 263145 (Uttarakhand)
}

\begin{abstract}
The public transport operators are essential to the efficiency and safety of the public transit system, which in turn, relies upon the safety and well-being of transit operators in the performance of their jobs. The physical and psychological health of the transit operators is a critical factor in the driving performance. Any impairment could lead to undesirable consequences for the passengers. Transit operators develop important, common diseases and injuries to which their work is likely to be a causal or contributing factor. Such injuries and diseases have been identified by a substantial body of scientific research, including epidemiologic and mechanismbased studies. The major health outcomes of concern are cardiovascular diseases, which include hypertension, heart disease and stroke; lung and bladder cancer and possibly other cancers; emphysema and asthma; post-traumatic stress disorder and other stress-related psychological disturbances; along with low back pain and other musculoskeletal disorders. Most available studies address the risk of disease among bus drivers; however, comparable studies among subway, maintenance and other transit workers are very limited. Occupational hazards of transit operators are uncommonly diverse and encompass much of the spectrum of occupational health. They include chemical, safety, ergonomic, physical, psychological and biological hazards. These exposures are matched to important, sometimes life-threatening outcomes, such as asbestos exposure and lung cancer; hypertension and heart disease; traumatic death and post-traumatic stress disorder; live electricity and electrocution; and vibration and disabling back injuries. Such diversity of hazards and associated diseases and injuries in a single industry is highly unusual in occupational health and presents an extraordinary opportunity for synergy in causing ill health. Despite new technological solutions and attempts to improve the working conditions during driving of vehicles, city bus drivers are still exposed to negative impacts of noise and vibrations, causing stress, increased fatigue and leads to numerous diseases. Therefore it seems merited to investigate the cabin ergonomics and the working conditions during the operation of transit vehicles, widely used in public transport systems. The main purpose of this research was to show the impacts that the conditions at work might have on bus drivers. No extensive major research was found to be done to investigate the influence of the conditions at work on functional stability of bus drivers. Investigation of vehicle in working (normal) environment are led rarely. Measurements often are done in idle run or during ride at maneuvering site only for 2-3 min. In this research results are presented for 4 h. until ride. All measurements are done in working environment on streets with passengers on board. Detailed numerical analysis of physical parameters like noise, light, temperature and humidity in the driver's cabin as well as physiological parameters like heart rate and grip strength are presented.
\end{abstract}

Keywords: ergonomics, occupational health, energy expenditure, heart rate, public transport operators

\section{Introduction}

Ergonomics is the science of designing user interaction with equipment and workplaces to fit the user. It is employed to fulfill the two goals of health and productivity. Ergonomics in the workplace has to do largely with the safety of employees, both long and short-term. Through ergonomics, workplaces can be designed so that workers do not have to overextend themselves.

Physical work results changes in:

- Oxygen consumption rate,

- Heart rate,

- Pulmonary ventilation rate,

- Body temperature, and

- Lactic acid concentration in the blood.

Studies have shown that there are marked health differences for urban bus driving compared to other occupations. Holme et al. (1980) conducted a study of 14,677 Norwegian males aged between 40 and 49 drawn from a group of different occupations. Bus drivers were one of the professionals with worst health, based on a range of health indicators (e.g., serum cholesterol levels, systolic blood pressure, and body weight). More specifically, the literature indicates three salient categories of morbidity prominent in populations of bus drivers; cardiovascular disease, gastrointestinal disorders, and musculoskeletal problems (Backman, 1983; Winkleby et al., 1988).

There are several main risk factors associated with the development of coronary heart disease and some studies have indeed corroborated that bus drivers have a high risk of developing CHD due to various risk factors. Ischemic heart disease (hardening of the coronary vessels) has been found to be greatest in the following profile of middle aged male drivers of ages between 50 and 59 years (Morris et al., 1970).

Cardiovascular disease has also been linked to high threatavoidant vigilant work where a high level of continued alertness needs to be maintained (Belkic et al., 2000). Driving can be conceptualised as such a task, with strain for bus drivers arising from the awareness to safeguard passengers from traffic hazards (Joshi et al., 2007).

Early findings that bus drivers are liable to suffer ill health as a result of the job remain true today. The lifestyle of the bus driver at home and at work is inextricably linked to his physical and psychological health.

Thus, the review calls for a raised awareness for the health and safety issues relevant to public transport operators as well as of the consequences, both to health and productivity of the drivers when subjected to work related disorders. By 


\section{International Journal of Science and Research (IJSR) \\ ISSN (Online): 2319-7064 \\ Index Copernicus Value (2013): 6.14 | Impact Factor (2014): 5.611}

improving the 'human side' of the role, it can be expected that the efficiency of this sector will be enhanced for drivers and passengers alike.

\section{Methodology}

A sample of 120 public transport operators was selected purposively from the selected area to carry out the study. Buses running on the same route were required to get a homogeneous fact sheet of the problem under study. So purposively four bus service providers namely Vijay bus service, Kanchan bus service, Om Sai bus service and Choudhary bus service were selected who provided their service on the same route from Gorakhpur to Salempur. This route was selected because of being easily approachable, familiarity with route and surrounding, limited resources and time on the part of the researcher.

Purposive random sampling was done to select the drivers from four different service providers who had first hand experience of working as a driver with the phenomenon of interest and a driving experience of at least ten years and had an accident free record of the past five years.

There is a linear correlation between the Heart rate - Oxygen consumption - total ventilation and the physical work performed by an individual. Of these, the first two Heart rate and Oxygen consumption rate are the most widely used for measuring the physiological cost of human work.

The total physiological cost of a task consists not only of the energy expenditure during work but also the energy expenditure above the resting level during the recovery period, that is, until recovery is complete. Energy expenditure and cardiac capacity set limits to the performance of physical work and these two functions are often used to assess the degree of severity of physical work.

Ergonomic cost of selected activity i.e. driving a public transport vehicle was measured in terms of physiological and cardiovascular stresses by measuring the heart rate, energy expenditure, total cardiac cost of work, cardiac strain index and heart rate max. The readings were taken for the complete cycle, when the selected respondents performed the activity.

1) Heart rate- The heart rate of the selected public transport operators was measured using the 'Polar Heart Rate Monitor' and the readings were taken for the rest, work and recovery periods as well. The resting heart rate was taken 5 minutes before starting the journey, while the working heart rate was taken after completing nearly an hour of journey. Again the resting heart rate was measured just after cessation of work cycle.

2) Energy Expenditure- The energy expenditure rate of the selected public transport operators in the present investigation was estimated from the heart rate responses using the formula given by Varghese et al. (1994).

3) Physiological cost of work- The physiological cost of driving task performed by the selected respondents was calculated by the formula given by Singh et al. (2007).
4) Cardiac strain index- The cardiac strain index is a surrogate measure of the heart strength and is calculated with the help of working heart rate, resting heart rate and heart rate max.

5) Heart rate max- HR max is the highest heart rate an individual can safely achieve through physical work stress and depends on age. Various formulas are used to estimate individual maximum heart rates based on age, but maximum heart rates vary significantly between individuals. Even within a single elite sports team, such as Olympic rowers in their 20s, maximum heart rates can vary from 160 to 220 . The most common formula encountered, with no indication of standard deviation, is:

$\mathrm{HR}_{\text {max }}=220-$ age

This formula has been attributed to various sources, but is widely thought to have been devised in 1970 by William Haskell and Samuel Fox.

6)Muscular Fatigue in Terms of Grip Strength- For determination of the muscular fatigue while driving of a public transport vehicle, the grip strength of selected respondents was measured with the help of grip dynamometer, before and after the performance of work. The grip strength for both, left and right hands were measured at rest and after the work separately. Percentage changes in grip strength were also calculated for the same. Decreased grip strength was interpreted as grip fatigue of the muscles

\section{Results}

1) Heart rate- A greater reduction in heart rate after the work during the reference period indicates a better conditioned heart. Heart rate that do not drop by more than 12 beats/min, one minute after stopping the work are associated with an increased risk of death (Christopher $\boldsymbol{e t}$ al., 1999).

The average resting heart rate was recorded to be $91 \pm 8.31$ beats per minute, whereas the average working heart rate was found $111 \pm 6.40$ beats per minute and the average recovery heart rate of the selected public transport operators after completing the work cycle of nearly 4 hours was recorded to be $100 \pm 5.88$ beats per minute.

In an ideal work condition, the average peak heart rate over a work day should be less than about 110 beats per minute, which was calculated to be $119 \pm 7.13$ beats per minute for the selected activity. So, on the basis of the heart rate responses obtained in this study it can be concluded that the task of driving a public transport vehicle poses a risk of cardio-vascular injury on the drivers of the same.

\section{Volume 4 Issue 12, December 2015}




\section{International Journal of Science and Research (IJSR) ISSN (Online): 2319-7064 \\ Index Copernicus Value (2013): 6.14 | Impact Factor (2014): 5.611}

Table 1: Physiological work load of the driving task performed by public transport operators

\begin{tabular}{|c|c|c|}
\hline Parameter & Mean & SD \\
\hline $\begin{array}{c}\text { Average Resting Heart Rate (beats per } \\
\text { min) }\end{array}$ & 91 & \pm 8.31 \\
\hline $\begin{array}{c}\text { Average Working Heart Rate (beats } \\
\text { per min) }\end{array}$ & 111 & \pm 6.39 \\
\hline $\begin{array}{c}\text { Average Recovery Heart Rate (beats } \\
\text { per min) }\end{array}$ & 100 & \pm 5.87 \\
\hline Average Heart Rate (beats per min) & 111 & \pm 6.39 \\
\hline Heart Rate Peak (beats per min) & 119 & \pm 7.12 \\
\hline Energy Expenditure (kJ/min) & 8.92 & \pm 1.01 \\
\hline Energy Expenditure Peak (kJ/min) & 10.22 & \pm 1.13 \\
\hline $\begin{array}{c}\text { Cardiac Cost of Work (CCW) (beats } \\
\text { per min) }\end{array}$ & 26640.72 & \pm 1535.15 \\
\hline $\begin{array}{c}\text { Cardiac Cost of Recovery (CCR) } \\
\text { (beats per min) }\end{array}$ & 48 & \pm 38.52 \\
\hline $\begin{array}{c}\text { Total Cardiac Cost of Work (TCCW) } \\
\text { (beats per min) }\end{array}$ & 26688.68 & \pm 1542.37 \\
\hline $\begin{array}{c}\text { Physiological Cost of Work (PCW) } \\
\text { (beats per min) }\end{array}$ & 111 & \pm 6.42 \\
\hline Cardiac Strain Index (CSI) (percent) & 23.583 & \pm 8.873 \\
\hline Heart Rate Max (beats per min) & 175.325 & \pm 5.018 \\
\hline
\end{tabular}

2)Energy Expenditure- The average energy expenditure rate when calculated for driving of a public transport vehicle was found to be $8.92 \mathrm{~kJ} / \mathrm{min}$ with a standard deviation value of 1.017. The average energy expenditure peak was calculated to be $10.22 \mathrm{~kJ} / \mathrm{min}$.

3) Physiological cost of work- The mean physiological cost of the task was found to be 111 beats per minute with a SD value of \pm 1.407 .

The physiological classification of different activities have been proposed by different researchers in the field of work physiology and ergonomics from time to time. They are either based on the monitoring of some principal parameters such as heart rate, both during work and recovery, energy cost or on some derived parameters i.e. net cardiac cost. The severity of the work load as per the physiological responses of heart rate and energy expenditure rate were analyzed for the public transport vehicle operators against the classifications given by ICMR (1969), Astrand and Rodahl (1977), Grandjean (1982), Varghese (1994) and NIOSH (USA) and ISO-28996(2006).

Table 2: Classification of physiological work according to severity of workload

\begin{tabular}{|c|c|c|c|c|c|c|c|c|c|}
\hline \multirow[t]{2}{*}{$\begin{array}{l}\text { Physiological } \\
\text { work load }\end{array}$} & \multicolumn{2}{|c|}{$\begin{array}{c}\text { Astrand and } \\
\text { Radahl (1977) }\end{array}$} & \multicolumn{2}{|c|}{ Grandjean (1982) } & \multicolumn{2}{|c|}{ Varghese et al. (1994) } & \multicolumn{2}{|c|}{$\operatorname{ICMR}(1969)$} & \multirow{2}{*}{$\begin{array}{c}\text { NIOSH (USA) Stand } \\
I S O-28996(2006) \\
\text { EE }(\mathrm{kj} / \mathrm{min})\end{array}$} \\
\hline & \begin{tabular}{|c|}
$E E$ \\
$(k J / m i n)$
\end{tabular} & $\begin{array}{l}\text { HR (Beats/ } \\
\text { min) }\end{array}$ & $\begin{array}{c}E E \\
(\mathrm{~kJ} / \mathrm{min})\end{array}$ & $\begin{array}{l}\text { HR (Beats/ } \\
\text { min) }\end{array}$ & $E E(\mathrm{~kJ} / \mathrm{min})$ & $\begin{array}{l}H R \text { (Beats/ } \\
\text { min) }\end{array}$ & $\begin{array}{c}E E \\
(k J / m i n)\end{array}$ & $\begin{array}{c}\text { HR (Beats/ } \\
\text { min) }\end{array}$ & \\
\hline Very light & & & & & Upto 7.0 & Upto 75 & $<1.75$ & $<75$ & $20 .-4.9$ \\
\hline Light & $<10$ & $<90$ & $<13$ & $<90$ & $7.1-10.5$ & $75-100$ & $1.75-3.5$ & $75-100$ & $5.0-7.4$ \\
\hline Moderately heavy & $10-20$ & $90-100$ & $13-18$ & $90-110$ & 10.614 .0 & $101-125$ & $3.5-5.25$ & $100-125$ & $7.5-9.9$ \\
\hline Heavy & $20-30$ & $110-130$ & $18-22$ & $110-130$ & $14.1-17.5$ & $126-150$ & $5.25-7.0$ & $125-150$ & $10.0-12.4$ \\
\hline Very heavy & $>30$ & $>130$ & $>22$ & $>130$ & $17.6-21.0$ & $151-175$ & $7.0-8.75$ & $150-175$ & $>12.5$ \\
\hline Extremely heavy & & & & & Above 21 & 175 above & 78.75 & $>175$ & \\
\hline
\end{tabular}

With the average energy expenditure rate of $8.92 \mathrm{~kJ} / \mathrm{min}$, the task of public transport vehicle operators fell under the category of light work as per the classification given by Astrand and Rodahl (1977), Grandjean (1982) and Varghese (1994). But when compared with the classification given by ICMR (1969), it was found to be a extremely heavy task and a hard task as per the classification of work load based on the energy expenditure rates given by NIOSH (USA) and ISO-28996 (2006).

For the present problem under investigation, the average working heart rate was recorded to be 111 beats per minute, and with this value the task of driving a public transport vehicle was found to be a heavy work as per the classification by Astrand and Rodahl (1977), Grandjean (1982), but as per the classification by ICMR (1969) and Varghese (1994), it was found to be a moderately heavy task.

Based on the scales of heaviness of the physiological work, it appeared that driving a public transport vehicle represented a work of heavy intensity.

4) Cardiac strain index- The cardiac strain index in the present study was calculated as 24.04 percent with SD value of \pm 8.873 .
5) Heart rate max- The maximum heart rate for the selected respondents was calculated using equation given by William Haskell and Samuel Fox (1970) and was obtained to be $175 \pm 5.018$ beats per minute.

6) Muscular Fatigue in Terms of Grip Strength- The findings showed that the average grip strength at rest was high i.e. $262.12 \mathrm{~N}$ and $241.52 \mathrm{~N}$ for the left and right hands, respectively but was decreased considerably by the difference values of $74.36( \pm 2.475)$ and $97.81( \pm 1.892)$ corresponding to the average grip strength after work values of $187.76 \mathrm{~N}$ and $143.71 \mathrm{~N}$ for the left and right hands, respectively. The percentage change in grip strength of both the hands was calculated using the formula $\mathrm{Sr}-\mathrm{Sw} / \mathrm{Sr} * 100$ and was found to be 28.36 percent $( \pm 10.157)$ for the left hand and 40.49 percent $( \pm 7.67)$ for the right hand.

The difference in the grip strength of right hand before and after work performance and also the percentage change in the grip strength of the same were found to be higher than that of left hand.

\section{Conclusion}

A heavy price accompanies the years on the job. The very skills which get the driver through a working day are, in fact, a quiet displacement of the burden onto his target organs; the heart, the blood vessels, the gastrointestinal tract,

\section{Volume 4 Issue 12, December 2015}

www.ijsr.net

Paper ID: NOV152041 


\section{International Journal of Science and Research (IJSR) \\ ISSN (Online): 2319-7064 \\ Index Copernicus Value (2013): 6.14 | Impact Factor (2014): 5.611}

the musculoskeletal system. It has been shown both in laboratory simulation and field studies that the experienced drivers who silently cope and seemingly automatically handle the continuous barrage of potential dangers and who toughly deny how difficult this work is, are those who show the most dramatic blood pressure and electrocardiographic responses to these threatening stimuli of the traffic environment. Reviews of the literature show that professional drivers are second to none as an occupational group at risk for hypertension and ischemic heart disease and that these diseases occur at a relatively young age.

Dr. June Fisher has stated that the urban transit operator represents the "eyes and the ears of the city". Stated another way, the troubles of the urban transit operator are the troubles of us all in the city. But, the corollary would read: the health of the city transit driver is inextricably linked to the health of the city. Efforts in the latter direction are therefore in the interest of us all.

\section{References}

[1] Anderson,T.E. 2008. Effects of acute alcohol intoxication on spinal cord vascular injury. Journal of Neuro Trauma 3:183-192.

[2] Backman, A. L. and Ja"rvinen, E. 1983. Turnover of professional drivers. Scandinavian Journal of Work, Environment and Health. 9: 36-41.

[3] Belkic, K.; Landsbergis, P. A.; Schnall, P.; Baker, D.; Theorell, T. and Siegrist, J. 2000. Psychosocial factors: Review of the empirical data among men. Occupational Medicine: State of the Art Reviews. 15: 24-46.

[4] British Crime Survey. 2006. An empirical investigation of job stress, social support, service length and job strain. Organizational Behaviour and Human Performance, $27: 279-302$.

[5] Brown, I. D. 2005. Driver fatigue. Human Factors. 36: 298-314.

[6] Chaudhary, S.S. 2010.Prevalence of cardiovascular diseases risk factors among auto-rickshaw drivers.Indian journal of community health.22(2):32-34.

[7] Christopher, R.; Cole, M.D.; Eugene, H.; Blackstone, M.D.; Fredric, J.; Pashkow, M.D.; Claire, E.; Snader, M.A.; Michael, S. and Lauer, M.D. 1999. Heart-Rate Recovery Immediately after Exercise as a Predictor of Mortality. NEJM, 341:13511357, Abstract online.

[8] Evans, G. W. and Johansson, G. 2008. Urban bus driving: An international arena for the study of occupational health psychology. Journal of Occupational Health Psychology. 3: 99-108.

[9] Holme, I.; Helgeland, A.; Hjermann, I.; Leren, P. and Lund-Larsen, P. G. 1980. Coronary risk factors in various occupational groups: The Oslo study. British Journal of Preventive and Social Medicine. 31: 96-100.

[10] http://www.answers.com/topic/heart-rate - cite notemhrt-4. Retrived 7 March 2011, 11.15 A.M.

[11] http://www.biologyonline.org/dictionary/Muscle fatigue. Retrived may 2011, 1.00 P.M.
[12] Joshi, M. S.; Senior, V. and Smith, G. P. 2007. A diary study of the risk perceptions of road users. Health, Risk and Society. 3: 261-279.

[13] Kompier, M. A. J. and Di Martino, V. 2005. Review of bus drivers-occupational stress and stress prevention. Stress Medicine. 11: 253-262.

[14] Morris, J. N.; Kagan, A.; Pattison, D. C.; Gardner, M. J. and Raffles, P. A. B. 1970. Incidence and prediction of ischaemic heart-disease in London busmen. The Lancet. 2: 553-559.

[15] Singh, S. P.; Mathur P., and Rathore, M. 2007. Weeders for drudgery reduction of women farm workers . India. Journal of Agricultural Engineering .44(3): 33- 38 .

[16] Varghese, M.A.; Saha, P.N. and Atreya, N. 1994. A rapid appraisal of occupational workload from a modified scale of perceived exertion. Ergonomics, 37(3): 485-491.

[17] Winkleby, M. A.; Ragland, D. R.; Fisher, J. M. and Syme, S. L. 1988a. Excess risk of sickness and disease in bus drivers: A review and synthesis of epidemiological studies. International Journal of Epidemiology. 17: 255261. 